\title{
Correction to: Framework for firm-level performance evaluations using multivariate linear correlation with MCDM methods: application to Japanese firms
}

\section{Joseph Junior Aduba ${ }^{1}$ (D)}

Published online: 1 November 2021

(C) The Japan Section of the Regional Science Association International 2021

\section{Correction to: Asia-Pacific Journal of Regional Science https://doi.org/10.1007/s41685-021-00213-8}

In the original publication of the article, equation of "Total Factor Productivity" was published incorrectly in Table 2 . The correct equation is provided below,

$$
T F P=\frac{R e v}{O P C}
$$

In addition, Eq. 1 was published incorrectly and the correct equation is provided below,

$$
\mu_{\tilde{A}}(x)= \begin{cases}0 & x \leq \mathrm{a}_{1} \\ \frac{x-\mathrm{a}_{1}}{a_{2}-a_{1}} & \mathrm{a}_{1}<x \leq \mathrm{a}_{2} \\ \frac{a_{3}-x}{a_{3}-a_{2}} & \mathrm{a}_{2}<x \leq \mathrm{a}_{3} \\ 0 & x>\mathrm{a}_{3}\end{cases}
$$

The original article was updated.

Publisher's Note Springer Nature remains neutral with regard to jurisdictional claims in published maps and institutional affiliations.

The original article can be found online at https://doi.org/10.1007/s41685-021-00213-8.

Joseph Junior Aduba

adubajj@gmail.com

1 Graduate School of Economics, Ritsumeikan University, 1-1-1 Noji-higashi, Kusatsu,

Shiga 525-8577, Japan 